\title{
An insight into As(III) adsorption behavior on $\beta$-cyclodextrin functionalized hydrous ferric oxide: Synthesis \& characterization
}

\author{
I. Saha ${ }^{1}$, K. Gupta ${ }^{2}$, S. Ahmed ${ }^{1}$, D. Chatterjee ${ }^{3}$ \& U.C. Ghosh ${ }^{2}$ \\ ${ }^{1}$ Department of Chemistry, Sripat Singh College, Murshidabad, India \\ ${ }^{2}$ Department of Chemistry, Presidency University, Kolkata, India \\ ${ }^{3}$ Department of Chemistry, University of Kalyani, Kalyani, West Bengal, India
}

\begin{abstract}
The particular study explores the adsorption potential of As(III) on $\beta$-cyclodextrin functionalized hydrous ferric oxide (HCC). This is characterized by XRD, FESEM, AFM, XPS, BET, surface site concentration and FTIR. The modification of hydrous ferric oxide (HFO) surface by $\beta$-cyclodextrin provides copious $-\mathrm{OH}$ groups which in turn enhances As(III) adsorption on HCC compared to HFO. The adsorption remains almost constant in $\mathrm{pH}$ range 3-8 which decreases at higher $\mathrm{pH}(>8)$ and followed monolayer and pseudo first order kinetics. It is spontaneous at $303 \mathrm{~K}$ with increasing entropy and decreasing enthalpy. Thus HCC is found to be a more efficient adsorbent media compared to HFO.
\end{abstract}

\section{INTRODUCTION}

The metalloid arsenic (As) which has been inflicting havoc on mankind for the past few decades and has assumed global proportions transcending geographical boundaries and communities, has targeted water which is the support system of a civilization as the medium for its transportation into the environment and biological systems which explains the countless deaths it has left behind in its wake (Biswas et al., 1998; Smedley \& Kinniburgh, 2002). The cases of As poisoning through drinking water can be traced long back in the world history (Ritchie, 1961; Vaughan, 2006; Wang et al., 2007). In 1898, the first cases of skin cancer were observed among population consuming As contaminated water in Poland. Since then it has been conclusively established that unabated ingestion of As via drinking water causes a variety of carcinogenic effects of skin, liver, kidney and other organs which ultimately leads to death. All these incidents have led to World Health Organization (WHO) and other national agencies to fix the permissible limit to $10 \mu \mathrm{g} \mathrm{L}^{-1}$ of As in drinking water. The principle source of As contamination is groundwater and the majority of rural and semi urban population in vast parts of the globe depend on this form of water for their drinking water and other household needs. The problem associated with As contamination is severe in Bangladesh and major parts of West Bengal, India. In West Bengal, more than 6 million people from 12 districts covering 111 blocks are worst affected and consuming drinking water with As concentration $>50 \mathrm{mg} \mathrm{L}^{-1}$ (Mazumder et al., 2010). The present investigations provide promising results demonstrating that HFO modified by $\beta$-cyclodextrin would be a better scavenger of As(III) from contaminated groundwater as against conventional pure HFO.

\section{METHODS/EXPERIMENTAL}

A ferric chloride solution was prepared in $0.1 \mathrm{M} \mathrm{HCl}$ and mixed with an aqueous solution of $\beta$-cyclodextrin. The mixture was warmed at $90^{\circ} \mathrm{C}$ accompanied by gradual addition of dilute $\mathrm{NH}_{3}$ solution with constant stirring till the $\mathrm{pH}$ reached around 7 . The dark brown precipitate formed was aged for $48 \mathrm{~h}$, filtered, and washed repeatedly with deionized water. The filtered mass obtained was dried at $100^{\circ} \mathrm{C}$ into an air oven. The fully dried mass was ground in a mortar and sieved to obtain a particle size between 52-100 mesh (250-150 microns) and subsequently used for adsorption studies.

\section{RESULTS AND DISCUSSION}

Figure 1A shows the XPS spectra of HCC. The peak at $711.9 \mathrm{eV}$ (spectrum 1B) is due to the $2 \mathrm{p}$ electron of Fe and peak at $532.0 \mathrm{eV}$ (spectrum 1C) value indicates the $\mathrm{O} 1 \mathrm{~s}$ electron. The peak at $286.1 \mathrm{eV}$ showed the presence of C-OH/C-O-C bonds on the HCC surface which clearly reveals that HFO was modified with $\beta$-cyclodextrin.

As(III) adsorption was observed to slightly decrease up to $\mathrm{pH}_{\mathrm{i}} 8.0$ for $\mathrm{HCC}$. Above this $\mathrm{pH}_{\mathrm{i}}$ value the adsorption decreased markedly up to $\mathrm{pH} 11.0$. At $\mathrm{pH}_{\mathrm{i}} 7.0,65.8 \% \mathrm{As}(\mathrm{III})$ uptake was observed for pure HFO whereas for HCC $81.5 \%$ of the total As(III) 
were removed from solution. When the initial solution $\mathrm{pH}$ was raised to 9.0 the $\mathrm{As}(\mathrm{III})$ adsorption dropped down to $66.3 \%$ for HCC. The $\mathrm{pH}_{\mathrm{ZPC}}$ value of $\mathrm{HCC}$ lied within the range 7.6-7.9 indicating that below this $\mathrm{pH}$ range the surface charge of $\mathrm{HCC}$ was positive and above it surface becomes negative. At low $\mathrm{pH}$ the most dominant form of As(III) species present in the solution is $\mathrm{As}(\mathrm{OH})_{3}\left(\mathrm{pK}_{1}=9.2\right)$. Due to the presence of large number of surface $-\mathrm{OH}$ groups the neutral $\mathrm{As}(\mathrm{OH})_{3}$ species form strong $\mathrm{H}$-bond with $\mathrm{HCC}$ surface at low $\mathrm{pH}$ region.

\section{CONCLUSIONS}

Hydrous ferric oxide (HFO) has proven to be a potent adsorbent for dissolved As(III) in contaminated water. However, surface modification of HFO with $\beta$-cyclodextrin by a simple and economical route shows large enhancement of As(III) scavenging power. The systematic As(III) adsorption by this material has showed that the optimum $\mathrm{pH}$ and equilibrium contact time are $\sim 7.0 \pm 0.1$ and $120 \mathrm{~min}$, respectively. The pseudo first-order equation describes the kinetic data $(\mathrm{pH}, 7.0 \pm 0.1$; temperature, $303 \pm 1.6 \mathrm{~K})$ well. The equilibrium data $(\mathrm{pH}, 7.0 \pm 0.2$; temperatures $( \pm 1.6 \mathrm{~K}), 288,303,318$ and 333 ) fit very well with the Langmuir isotherm model. The Langmuir monolayer adsorption capacity is $66.96 \pm 9.16(\mathrm{mg}$ of As per g. of $\mathrm{HCC}$ ) at $303 \mathrm{~K}$, and that increases
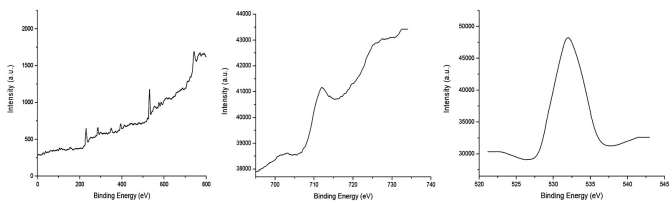

Figure 1. XPS of (1A) HCC, (1B) Fe 2p spectrum and (1C) O 1 s spectrum. with increasing temperature. The adsorption reaction is spontaneous $\left(\Delta \mathrm{G}^{\circ}=\right.$ negative $)$ and exothermic $\left(\Delta \mathrm{H}^{\circ}=\right.$ negative $)$, and that takes place with increasing entropy $\left(\Delta S^{\circ}=0.007\right)$. The energy $\left(\mathrm{kJ} \mathrm{mol}^{-1}\right)$ of As(III) adsorption and the FTIR analysis have suggested that the As(III) adsorption on HCC is of both physisorption as well as chemisorption in nature. The As(III) adsorption by HCC is negatively influenced by phosphate and sulfate ions. The regeneration of As(III) adsorbed material is possible maximum up to $75 \%$ with $1 \mathrm{M} \mathrm{NaOH}$ solution.

\section{ACKNOWLEDGEMENTS}

The authors are thankful to Sripat Singh College for providing laboratory facilities.

\section{REFERENCES}

Biswas, B.K., Dhar R.K., Samanta, G., Mandal, B.K., Faruk, I., Islam, K.S., Chowdhury, M.M., Islam, A., Roy, S. \& Chakraborti, D. 1998. Detailed study report of Samata, one of the arsenic affected villages of Jessore district, Bangladesh. Curr. Sci. 74(2): 134-145.

Mazumder, D.N.G., Ghosh, A., Majumdar, K.K., Ghosh, N., Saha, C. \& Mazumder, R.N.G. 2010. Arsenic contamination of ground water and its health impact on population of district of Nadia, West Bengal. India. Indian J. Community Med. 35(2): 331-338.

Ritchie, J.A. 1961. Arsenic and antimony in some New Zealand thermal waters. NZJ Sci. 4: 218-229.

Smedley, P.L. \& Kinniburgh, D.G. 2002. A review of the source, behaviour and distribution of arsenic in natural waters. Appl. Geochem. 17(5): 517-568.

Vaughan, D.J. 2006. Arsenic, Elements 2: 71-75.

Wang, L., Chen, A.S.C., Tong, N. \& Coonfare, C.T. 2007. Arsenic removal from drinking water by ion exchange, U.S. EPA demonstration project at Fruitland, ID, six month evaluation report. EPA/600/R-07/017. United States Environmental Protection Agency, Water Supply and Water Resources Division, National Risk Management Research Laboratory, Cincinnati, $\mathrm{OH}$. 